\title{
O Ciclo Investigativo no ensino de conceitos estatísticos
}

\author{
Eurivalda Ribeiro dos Santos Santana \\ Irene Maurício Cazorla
}

\begin{abstract}
Resumo: Ao longo dos anos, o ensino de conceitos matemáticos tem sido investigado no propósito de compreender metodologias de ensino nas quais o estudante seja protagonista. Com o objetivo de ampliar essa discussão e colaborar com as reflexões a respeito do ensino e da aprendizagem em Matemática é que, neste artigo, nos propomos discutir possibilidades metodológicas para o ensino de conceitos estatísticos por meio do uso de uma metodologia investigativa denominada de Ciclo Investigativo. Para isso, apresentamos reflexões teóricas, acompanhadas de exemplos de resultados no âmbito das pesquisas realizadas pelo Grupo de Pesquisa em Educação Matemática, Estatística e em Ciências. Os resultados evidenciam que ao implementar o Ciclo Investigativo em sala de aula é possível trabalhar com conceitos estatísticos, com contextos da realidade e princípios do pensamento científico.
\end{abstract}

Palavras-chave: Ciclo Investigativo. Conceitos Estatísticos. Pensamento Científico. Metodologia Investigativa.

\section{The Investigative Cycle for the teaching of statistical concepts}

\begin{abstract}
Over the years the teaching of mathematical concepts has been investigated in order to understand teaching methodologies in which the student is the protagonist. In order to expand this discussion and collaborate with reflections on teaching and learning in Mathematics, in this article, we propose to discuss the methodological possibilities for teaching statistical concepts, through the use of an investigative methodology called the Investigative Cycle. For this, the researchers present the theoretical reflections, accompanied by examples experienced in the scope of the researches carried out by the Grupo de Pesquisa em Educação Matemática, Estatística e em Ciências. The results show that when implementing the Investigative Cycle in the classroom it is possible to work with statistical concepts, with contexts of reality and principles of scientific thought.
\end{abstract}

Keywords: Investigative Cycle. Statistical Concept. Scientific Thought. Investigated Methodologies.

\section{El Ciclo Investigativo en la enseñanza de conceptos estadísticos}

Resumen: A lo largo de los años, se ha investigado la enseñanza de conceptos matemáticos para comprender las metodologías de enseñanza en las que el alumno es el protagonista. Para expandir esta

Eurivalda Ribeiro dos Santos Santana Doutora em Educação Matemática. Professora da Licenciatura em Matemática da Universidade Estadual de

Santa Cruz (UESC). Bahia, Brasil.

D https://orcid.org/0000-0001-6156-1205 $\bowtie$ eurivalda@uesc.br

Irene Maurício Cazorla Doutora em Educação. Professora do Programa de Pós-Graduação em Educação em Ciências e Matemática da Universidade Estadual de Santa Cruz (UESC). Bahia, Brasil.

D https://orcid.org/0000-0003-3028-5513

$\bowtie$ icazorla@uol.com.br

Recebido em 06/06/2020

Aceito em 22/09/2020

Publicado em 14/10/2020 discusión y colaborar con reflexiones sobre la enseñanza y el aprendizaje de las Matemáticas, en este artículo, proponemos discutir las posibilidades metodológicas para la enseñanza de conceptos estadísticos, mediante el uso de una metodología de investigación llamada Ciclo Investigativo. Para ello, los investigadores presentan las reflexiones teóricas, acompañadas de ejemplos experimentados en el ámbito de las investigaciones realizadas por el Grupo de Pesquisa em Educação Matemática, Estatística e em Ciências. Los resultados muestran que al implementar el Ciclo Investigativo en el aula es posible trabajar con conceptos estadísticos, con contextos de realidad y principios de pensamiento científico.

Palabras clave: Ciclo Investigativo. Conceptos Estadísticos. Pensamiento Científico. Metodología de Investigación. 


\section{Introdução}

O ensino de conceitos estatísticos no Ensino Fundamental vem sendo preconizado oficialmente no Brasil desde o advento dos Parâmetros Curriculares Nacionais (BRASIL, 1997, 1998). A Base Nacional Comum Curricular (BNCC), publicada oficialmente em dezembro de 2017, tem dentre seus principais objetivos o desenvolvimento de competências que são assumidas como a mobilização de conhecimentos, habilidades, atitudes e valores para resolver demandas complexas da vida cotidiana, para o exercício da cidadania e do mundo do trabalho no Ensino Fundamental (BRASIL, 2017).

Segundo a BNCC, os conceitos de Estatística estão contidos na Unidade Temática Probabilidade e Estatística, que é uma das cinco unidades da Matemática, juntamente com Números, Álgebra, Geometria e Grandezas e Medidas. As orientações para o ensino de conceitos estatísticos nesse nível escolar contemplam que "os cidadãos precisam desenvolver habilidades para coletar, organizar, representar, interpretar e analisar dados em uma variedade de contextos, de maneira a fazer julgamentos bem fundamentados e tomar as decisões adequadas." (BRASIL, 2017, p. 272).

Essas orientações enfatizam a necessidade de envolver a coleta e organização de dados de uma pesquisa, planejamento, construção, leitura e interpretação de tabelas e gráficos, a produção e comunicação de textos escritos a respeito dos dados coletados, com justificativa e conclusões e, portanto, precisam ser inerentes ao processo de ensino. 0 que se assemelha aos procedimentos de uma pesquisa científica entendida como "método de pensamento reflexivo, que requer um tratamento científico e se constitui no caminho para conhecer a realidade ou para descobrir verdades parciais" (MARCONI e LAKATOS, 2010, p. 139).

Para a sala de aula, definimos esse tipo de processo de ensino como uma metodologia investigativa, sendo um processo que organiza fases para um ensino com vistas à aprendizagem de determinados conceitos, por meio de princípios científicos, com o intuito de despertar nos estudantes 0 interesse pela pesquisa científica, além de possibilitar a formação de um cidadão crítico e reflexivo. Procedimentos que se referem à implementação de uma perspectiva de aula investigativa, pois emerge nos papéis do estudante e do professor o fomentar de princípios científicos. Nesse sentido,

é fundamental que 0 aluno se sinta à vontade e the seja dado tempo para colocar questões, pensar, explorar suas ideias e exprimi-las, tanto ao professor como aos seus colegas. $\mathrm{O}$ aluno deve sentir que as suas ideias são valorizadas e que se espera que as discuta com os colegas, não sendo necessária a validação constante por parte do professor (PONTE, BROCARDO e OLIVEIRA, 2013, p. 28). 
São diferentes tarefas que requerem a atuação do estudante e o envolvem como participante de seu próprio processo de aprendizagem de maneira ativa, pois aumenta "a flexibilidade cognitiva, que é a capacidade de alternar e realizar diferentes tarefas, operações mentais ou objetivos e de adaptar-nos a situações inesperadas, superando modelos mentais rígidos e automatismos pouco eficientes" (MORAN, 2018, p. 3). Numa metodologia investigativa, o papel do estudante se estabelece de maneira ativa, podendo participar desde elaboração do problema de pesquisa até a conclusão da investigação, respondendo a esse problema elaborado.

O perfil do professor é de mediador, que requer agilidade para resolver situações que não foram previamente planejadas para aquela aula, pois podem ser situações oriundas das observações do próprio problema que está sendo investigado, de decisões que precisam ser tomadas para a coleta de dados ou para a análise. A metodologia investigativa exige do professor o conhecimento da disciplina, conhecimento do currículo e conhecimento da experiência, esses são conhecimentos definidos por Tardif (2014).

Observando-se esse contexto é que, neste artigo, nos propomos discutir possibilidades metodológicas para o ensino de conceitos estatístico, por meio do uso de uma metodologia investigativa denominada de Ciclo Investigativo.

\section{O Ciclo Investigativo e a sala de aula de Matemática}

O ensino de Estatística em sala de aula pode ser desenvolvido como uma mera aplicação de fórmulas a um conjunto de dados que não possui sentido real, ou seja, números e categorias não conectados com situações ou com problemáticas colocadas a partir de um contexto real, 0 que levará a um ensino de fórmulas, entediante possivelmente pela quantidade de cálculos envolvidos e sem sentido, podendo frustrar a expectativa de aprendizagem.

Outra possibilidade para o ensino de Estatística é que os dados sejam oriundos de um contexto real e que tenham sentido para os estudantes. Neste caso, nos referimos a um contexto real como um conjunto de condições que envolvam o comportamento social, cultural ou dos hábitos dos estudantes, dos professores ou de um certo grupo de pessoas envolvidas em uma dada situação, bem como, da observação ou experimentação de fenômenos da natureza. Essas possibilidades se configuram num cenário importante para o grupo de estudantes da turma ou da escola.

É esse contexto real que vai proporcionar o trabalho com os dados em sala de aula dando sentido e significado aos conceitos estatísticos. Para isso, uma estratégia é que os estudantes 
tenham um papel ativo no processo de coleta e tratamento dos dados, que os dados sejam relativos a eles próprios, à sua comunidade ou por eles produzidos.

Para se trabalhar em contextos reais é preciso que o professor planeje tarefas que possibilitem essa abordagem para temas que se aproximem e despertem, ao máximo, o interesse do estudante.

Classificamos tarefas construídas para as ações em sala de aula em "sequência de ensino como um conjunto de situações elaboradas e dispostas de maneira que sejam abordados conceitos previamente selecionados para serem trabalhados" (SANTANA, 2012, p. 79). Uma sequência de ensino se predispõe em um planejamento que organiza uma ordem de apresentação de situações (tarefas), que prioriza graduar a apresentação de acordo com a complexidade inerente a um conceito ou por fases que organizam a confrontação dos estudantes com relações, propriedades e teoremas que se referem à operacionalização de um conceito. As situações devem dar sentido ao conceito, não se referindo apenas a comandos como: calcule, determine, encontre o valor de, dentre outros. Em outras palavras, essa organização precisa possibilitar a compreensão do conceito pelo estudante. 0 uso do termo sequência de ensino, busca se distanciar de um planejamento que selecione um conteúdo e organize uma lista de exercícios.

Neste estudo, as situações são tarefas preparadas e organizadas para dar sentido aos conceitos estatísticos selecionados e que são dispostas a partir das cincos fases do Ciclo Investigativo apresentado por Wild e Pfannkuch (1999). Os autores discutem os processos de pensamento que envolvem a resolução de problemas estatísticos, propondo a formulação de problemas até a conclusão de sua resolução.

O Ciclo Investigativo PPDAC, proposto por Wild e Pfannkuch (1999), é constituído por cinco fases (Figura 1), a saber: Problema (P), que diz respeito ao conhecimento do contexto dos dados, definição do problema ou fenômeno a ser investigado; Planejamento $(\mathrm{P})$, que inclui a definição das ações para a investigação; Dados (D), que inclui o processo de coleta de dados; Análise $(\mathrm{A})$, que diz respeito ao tratamento e a análise dos dados; e a Conclusão $(\mathrm{C})$, que encerra a investigação sobre o problema colocado com um posicionamento crítico, reflexivo, com a comunicação dos dados. A partir da conclusão é possível a geração de novas ideias e novos questionamentos. 


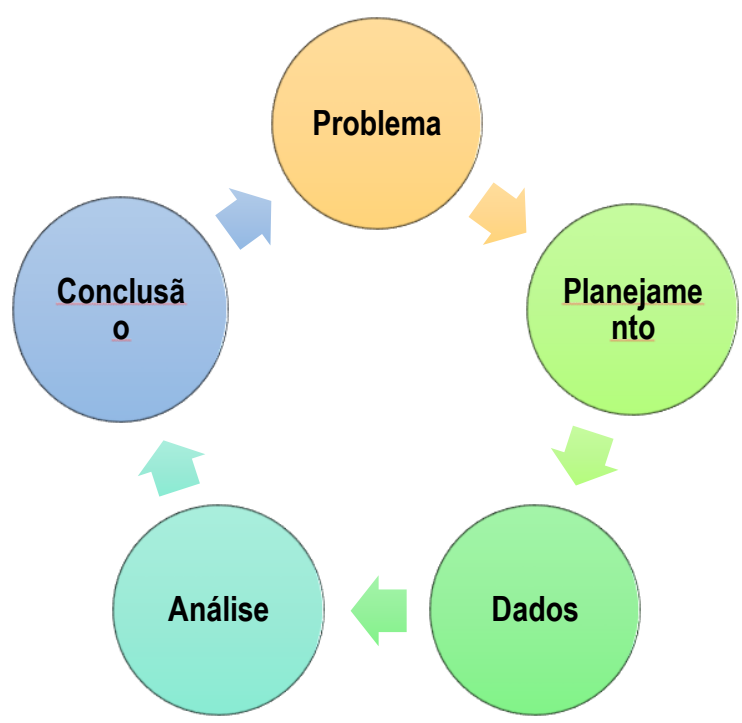

Figura 1: O Ciclo Investigativo (Esquema baseado em Wild e Pfannkuch, 1999)

As cinco fases são distribuídas de modo que se admite comparar as ações a serem desenvolvidas em sala de aula com as ações de uma pesquisa científica. Para se definir o Problema ou fenômeno a ser investigado, o professor pode discutir com os estudantes uma temática que seja do âmbito local ou global — epidemias, aumento de preços, poluição do meio ambiente -, ou mesmo dentro de um conteúdo de outra disciplina, como por exemplo, ciências, geografia, história - germinação das sementes, índice de massa corpórea, distribuição populacional, ciclo da seca. Essas são possibilidades, dentre muitas outras problemáticas, que podem surgir da realidade da comunidade escolar.

Escolhido o Problema ou fenômeno a ser investigado, é pertinente discutir seu contexto de maneira ampla: onde ocorre ou ocorreu, que população é envolvida na problemática escolhida, quais possibilidades de o problema ocorrer numa dada população. É preciso discutir sobre 0 problema e os pontos que o definem.

Com a determinação do problema e depois de ter identificado o seu contexto, se deve planejar, junto com os estudantes, as metas e objetivos a serem alcançados, definindo o melhor caminho para alcançá-los. É necessário refletir sobre a resposta que se quer alcançar - a que questão se quer responder - e como é possível alcançar a resposta. Qual o melhor instrumento a ser utilizado: um questionário, uma entrevista ou uma observação do fenômeno? Qual o melhor período para a coleta dos dados (aplicação dos instrumentos de pesquisa)?

Durante o planejamento deve-se definir de quem ou de que serão obtidos os dados, preparar os instrumentos de coleta de dados, selecionar a amostra da qual vai se coletar os dados e planejar o processo de coleta dos dados.

Após o planejamento ser constituído é preciso proceder à coleta de Dados. 0 estudante 
precisa ser preparado para realizar a coleta e pôr em prática a ética da pesquisa: preservando 0 anonimato do sujeito de pesquisa; respeitando as possíveis opiniões dos sujeitos pesquisados, caso se trate de uma pesquisa de opinião; ou de aferir atentamente os dados de um experimento, ou de fontes secundárias, como por exemplo, os dados da conta de água ou de energia.

Feita a coleta, os estudantes vão Analisar os dados. Fase em que o professor orienta 0 trabalho com os conceitos estatísticos. Sugerimos que diante das variáveis apresentadas nos formulários de coleta de dados, o professor apresente e discuta com os estudantes os conceitos estatísticos que serão trabalhados e, como eles devem ser tratados a fim de fornecer informações estatísticas relevantes. Quais tipos de gráficos e tabelas podem ser usados para um dado tipo de variável? Que medidas estatísticas podem ser feitas? Quando devemos utilizar a média, a mediana ou moda? Um número absoluto ou relativo?

Feitas as análises, segue-se para a fase da Conclusão. Nesta fase, é preciso atentar para a necessidade de responder à pergunta de investigação, da problemática posta ou do fenômeno investigado e a partir das informações estatísticas, concluir o Ciclo Investigativo. 0 professor orienta os estudantes para que extraiam conclusões baseada nos dados e não usar a própria opinião ou utilizar-se do que diz o senso comum, mas despertar no estudante a interpretação dos dados, a leitura das informações geradas a partir dos dados coletados.

Para tornar mais didático, vamos colocar um exemplo. Suponha que na aula de Ciências o professor esteja trabalhando a classificação dos animais e, decide investigar junto com os estudantes, o que eles pensam sobre o cuidado com os animais domésticos e o que pensam a respeito do costume da população em manter animais silvestres como animais domésticos. 0 professor inicia o diálogo com os estudantes, pontuando qual é o Problema que se quer investigar, por exemplo, pode elaborar: "quais são os animais de estimação favoritos da turma?"

Neste caso, será realizada uma pesquisa de opinião, na qual os sujeitos investigados serão os próprios estudantes, que comporão a população em estudo. O professor conduz o diálogo de modo a propiciar que os estudantes externem sua opinião sobre o significado de "animal de estimação favorito", que isso é diferente de se ter animal de estimação em casa, o que é um animal doméstico, o que é um animal silvestre, dentre outras possibilidades de discussão.

Nesse Problema, o contexto é o risco de extinção de alguns animais silvestres, as questões legais sobre a proibição da comercialização dos animais silvestres, a questão do tráfico, a ideia de se prender em cativeiro esses animais, dentre outros. Como definir o que é um animal silvestre? Como distinguir um animal silvestre de um animal nascido em cativeiro, como por 
exemplo, os periquitos que nascem em cativeiro?

Além disso, o professor pode criar condições para que o estudante identifique: qual a sua própria posição sobre o fato de prender um animal silvestre para ser um animal de estimação? Quais são os aspectos éticos que o estudante se refere? O quanto disso é normalizado pela comunidade que o estudante vive?

Uma vez elaborado o problema a ser investigado, e saber como os estudantes se posicionam sobre tratar um animal silvestre como um animal de estimação, é preciso iniciar a fase do Planejamento. Para isso, precisa planejar com os estudantes como pode realizar essa investigação, deixando que eles se posicionem. Por exemplo, pedir aos estudantes para listar os animais de estimação e anotar na lousa, depois pode pedir aos estudantes que levantem a mão e, assim, se terá um levantamento dos animais preferidos da turma. Neste caso, o Planejamento e a coleta de Dados serão realizados em uma única ação. Todavia, o professor não terá como reconstituir os dados, pois o fato de ter levantado a mão é temporário.

Outra forma, seria construir com os estudantes um pequeno instrumento composto pela questão de investigação e por outras, por exemplo, uma questão para saber o sexo do estudante, que permite estudar a relação entre a variável tipo de animal preferido e a variável sexo, possibilitando a emergência da ideia de associação entre variáveis. Na Figura 2 apresentamos um exemplo de instrumento de coleta de dados, no qual cada pergunta se torna uma variável estatística: sexo, animal de estimação favorito, posição sobre prender um animal silvestre e a razão desse posicionamento.

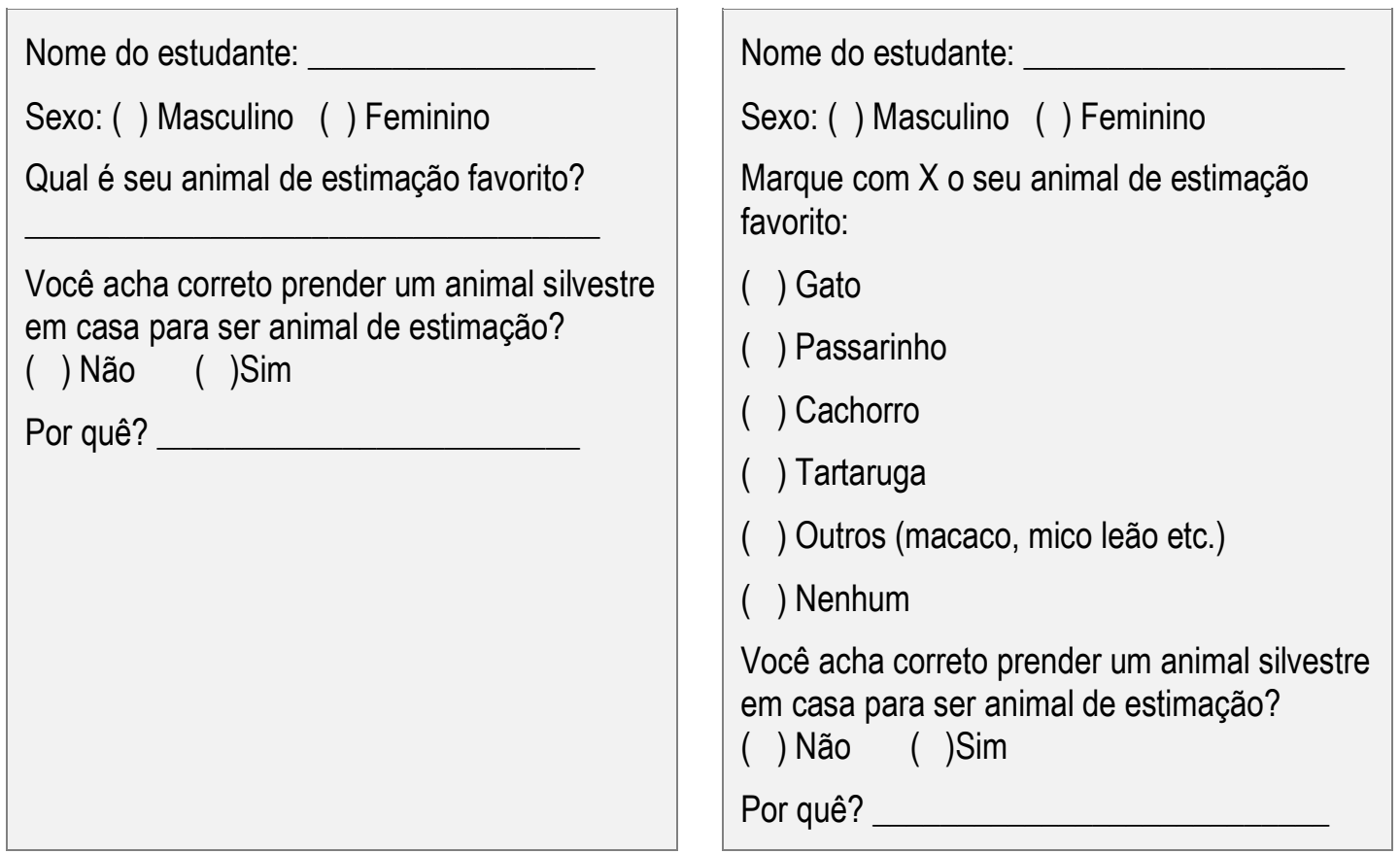

Figura 2: Exemplos da construção do instrumento de coleta de dados (Elaboração das Autoras) 
$\mathrm{Na}$ Figura 2, mostramos um modelo de instrumento para coleta de dados. Na pergunta "Qual é seu animal de estimação favorito?" o professor pode optar por ser "subjetiva" ou "objetiva". Se for subjetiva, como no caso do instrumento do lado esquerdo, os estudantes ficarão livres para expressar suas preferências, o que implica que o professor deverá estar atento para a classificação a posteriori. Se optar por ser uma questão "objetiva", como o instrumento da direita, com categorias definidas a priori será mais fácil o tratamento dos dados, porém poderá induzir os estudantes nas respostas, mascarando as reais preferências. Esta decisão é muito interessante de ser trabalhada na sala de aula. Outra questão é a categoria nenhum, que os estudantes costumam pensar que não é um dado.

Se a escolha da turma for construir o instrumento, depois de pronto, o professor pode imprimir e entregar para que cada estudante preencha, coletando os Dados.

Com os dados coletados, os estudantes podem iniciar a Análise, que consiste no tratamento dos dados. Se a turma optou pela coleta por meio do levantamento dos braços, a tabela de frequência fica automaticamente pronta na lousa. Se optou pelo instrumento, os estudantes precisarão sistematizar os dados na lousa. Para isso, poderia criar no papel madeira (papel metro) um banco de dados, onde as informações de cada estudante serão dispostas nas linhas e as variáveis em estudo nas colunas, como exemplificamos nas Figuras 3 e 4.

\begin{tabular}{|l|c|l|c|l|}
\hline Aluno & Gênero & Animal & $\begin{array}{c}\text { Acha } \\
\text { correto... }\end{array}$ & Por que? \\
\hline Ana & F & Gato & Não & Eles são do mato \\
\hline Bia & F & Cachorro & Não & Eles podem ferir as pessoas \\
\hline Afonso & M & Peixe & Sim & Ele estava ferido e morrendo de fome \\
\hline Carla & F & Coelho & Não & É proibido \\
\hline Diogo & M & Jabuti & Não & Eles devem ser livres \\
\hline$\ldots$ & $\ldots$ & $\ldots$ & $\ldots$ & $\ldots$ \\
\hline
\end{tabular}

Figura 3: Exemplo fictício com a pergunta aberta (Acerva da Pesquisa)

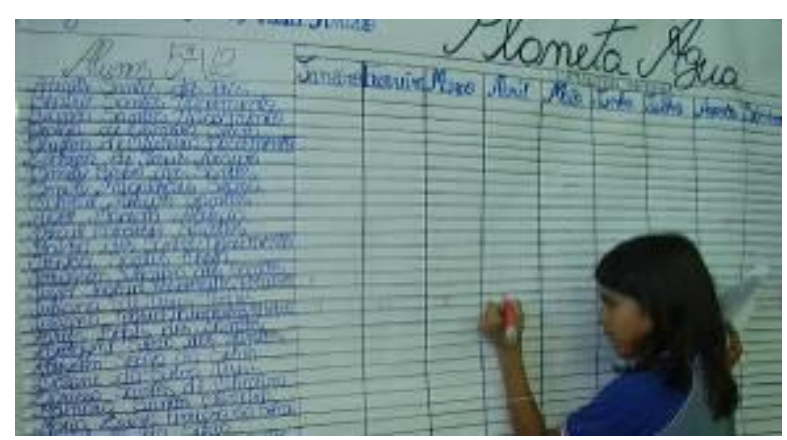

Figura 4: Exemplo de banco de dados do "Planeta água" (CAZORLA e SANTANA, 2010, p. 49)

A organização do banco de dados precisa ser feita pelos próprios estudantes, o professor apenas orienta. A Figura 4 ilustra a participação de uma estudante preenchendo um banco de dados, no qual cada estudante inseriu os dados de seu próprio instrumento. 
Disposto o banco de dados, procede-se às transformações de representação, que se refere a transformar a representação dos dados estatísticos, podem ser dos dados brutos para medidas estatísticas, tabelas ou gráficos e, depois, para a distribuição percentual. E esses serão os objetos matemáticos (conceitos estatísticos) a serem trabalhados na disciplina. A Figura 5 apresenta uma ilustração com possibilidades de transformações de representações de dados estatísticos.

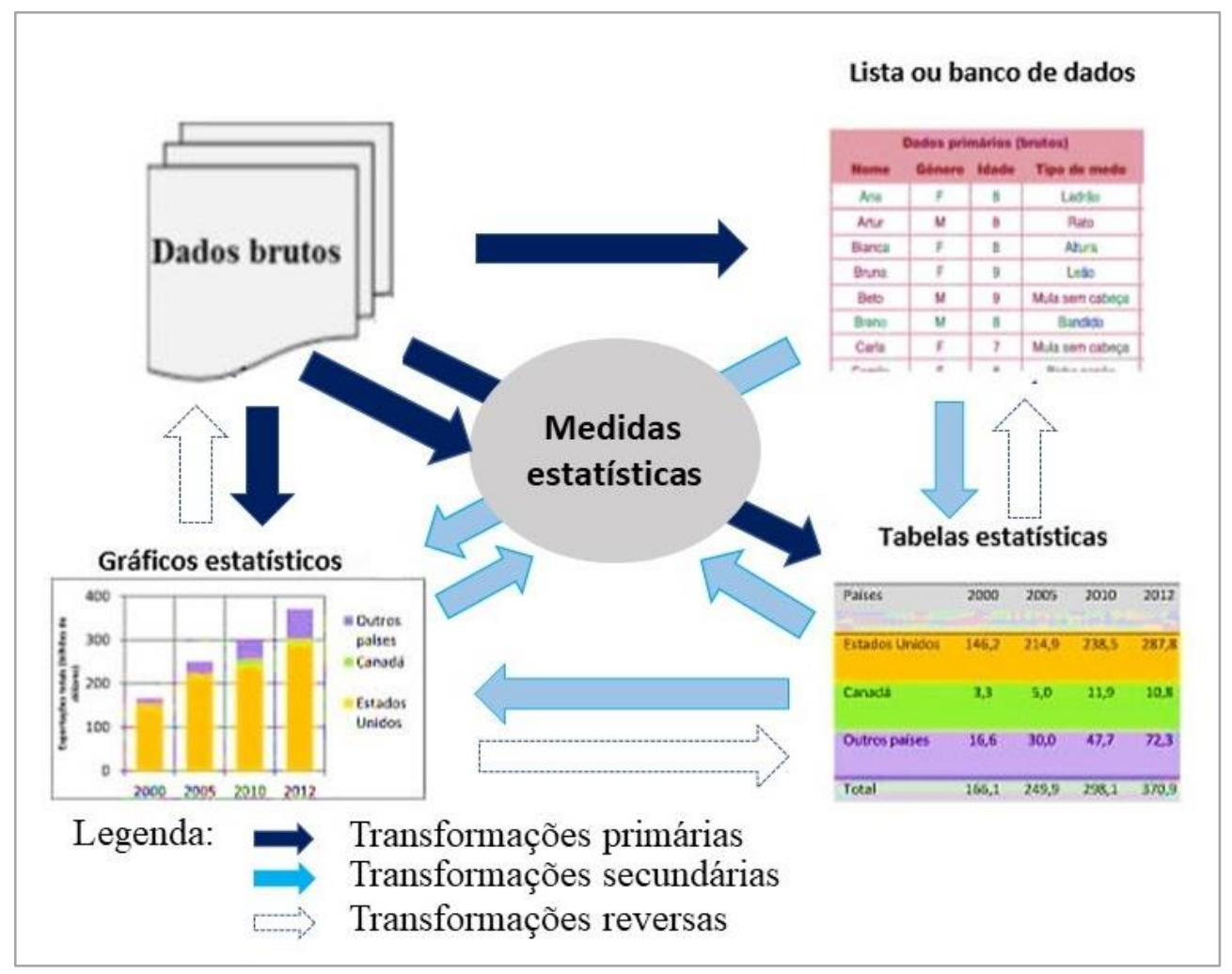

Figura 5: Transformações de representação de dados estatísticos (Adaptado de Silva Junior, 2018)

Na ilustração da Figura 5, observa-se que as transformações primárias ocorrem a partir dos dados brutos para o banco de dados, medidas, gráficos ou tabelas estatísticas. As secundárias são transformações que não têm os dados brutos como fonte principal, por exemplo, transformação da representação dos dados na tabela para gráficos estatísticos. A transformação reversa ocorre quando se transforma de gráfico para tabela ou para os dados brutos, também, pode ocorrer a transformação reversa da tabela para o banco de dados. A transformação reversa é a de maior complexidade. Essas possibilidades de transformações de representações de dados estatísticos precisam ser planejadas pelo professor, conforme 0 ano escolar dos estudantes e, no momento da análise, orientar os estudantes para a realização dessas.

As transformações de representação podem ser feitas utilizando lápis e papel, planilhas eletrônicas ou softwares estatísticos. $\mathrm{O}$ uso de computadores e dispositivos será feito conforme a disponibilidade para o manuseio do estudante. Qualquer que seja a ferramenta - lápis e papel, 
software, planilha eletrônica - o estudante assume o papel principal de construtor das representações e o professor de orientador do estudante.

A última fase é a Conclusão. O professor orienta os estudantes para que reflitam sobre os resultados e, a partir dos gráficos, tabelas e medidas estatísticas, elaborem conclusões, bem como inferências oriundas desses resultados, possibilitando que o estudante faça uma análise crítica, se posicionando a respeito do problema de investigação posto ou a respeito da temática abordada.

As fases do PPDAC podem ser trabalhadas conforme os tempos didáticos que são adotados por professores nas aulas de Matemática. Esses tempos privilegiam uma aula dialogada na qual o estudante é protagonista da sua aprendizagem e auxilia na construção dos saberes matemáticos. Matematizar com jogos e desafios: a dinâmica desse tempo prioriza a realização de uma atividade lúdica ou uma dinâmica, objetivando iniciar o primeiro contato com o conceito ou conteúdo matemático. Tempo que se relaciona com a primeira fase (Problema) do PPDAC, pois ocorre o primeiro contato da turma com o tema ou o problema de investigação, por meio de dinâmicas de diálogo. Matematizar na roda da conversa: tempo para socialização e registros coletivos dos saberes dos estudantes. O professor buscará explicitar, nesse momento, os conceitos matemáticos que estão envolvidos no que foi feito no tempo anterior (jogos e desafios), explorando relações e propriedades. Se associa a ações inerentes à primeira, segunda, quarta e quinta fases (Problema, Planejamento, Análise e Conclusão) do PPDAC; são momentos que a relação do tema com os conceitos estatísticos pode ser estabelecida num diálogo entre professor e estudante, e entre os estudantes. Matematizar com registros: tempo que prioriza o registro individual a partir de sua produção, realizar a interface entre as notações pessoais e a formalização matemática. Tempo que se assemelha a ações da segunda, terceira, quarta e quinta fases (Planejamento, Dados, Análise e Conclusão) do PPDAC, pois mobiliza os registros individuais e em grupo das representações e das transformações de representações estatísticas.

O Quadro 1 apresenta uma síntese das fases do PPDAC e o desenvolvimento delas em sala de aula na perspectiva da aula centrada em três tempos didáticos: matematizar com jogos e desafios; matematizar na roda de conversa; matematizar com registros (SANTANA et al., 2015).

Quadro 1: PPDAC e momentos da aula (procedimentos)

\begin{tabular}{|c|c|c|c|}
\hline Fases & Elemento & $\begin{array}{c}\text { Procedimento (Tempo } \\
\text { didático) }\end{array}$ & Exemplo \\
\hline Problema & $\begin{array}{c}\text { - Definição } \\
\text { (elaboração) do } \\
\text { problema. }\end{array}$ & $\begin{array}{c}\text { - Matematizar na roda de } \\
\text { conversa para definir e discutir } \\
\text { os elementos do assunto a ser }\end{array}$ & $\begin{array}{c}\text { - Discussão para definir a } \\
\text { problemática, tendo como } \\
\text { ponto de partida o "animal }\end{array}$ \\
\hline
\end{tabular}




\begin{tabular}{|c|c|c|c|}
\hline & $\begin{array}{l}\text { - Identificação do } \\
\text { problema. }\end{array}$ & $\begin{array}{c}\text { estudado. } \\
\text { - Matematizar com jogos e } \\
\text { desafios para contextualizar a } \\
\text { situação-problema e formular } \\
\text { questões de pesquisa. }\end{array}$ & $\begin{array}{l}\text { de estimação favorito". } \\
\text { - Definição do problema a } \\
\text { ser investigado: quais são } \\
\text { os animais favoritos da } \\
\text { turma? E como os } \\
\text { estudantes se posicionam } \\
\text { sobre tratar um animal } \\
\text { silvestre como um animal } \\
\text { de estimação. }\end{array}$ \\
\hline Planejamento & $\begin{array}{l}\text { - Esclarecer as } \\
\text { metas e objetivos } \\
\text { pretendidos, } \\
\text { definindo o melhor } \\
\text { caminho para } \\
\text { alcançá-los. } \\
\text { - Organização e } \\
\text { realização dos } \\
\text { trabalhos a serem } \\
\text { produzidos. }\end{array}$ & $\begin{array}{l}\text { - Matematizar na roda de } \\
\text { conversa para definir a } \\
\text { população a ser investigada. } \\
\text { - Matematizar com registro } \\
\text { para identificar e caracterizar } \\
\text { as variáveis. } \\
\text { - Elaboração dos } \\
\text { instrumentos. } \\
\text { - Planejamento da coleta dos } \\
\text { dados. } \\
\text { - Planejamento do tratamento } \\
\text { dos dados. } \\
\text { Nesses últimos pode ser tanto } \\
\text { matematizar na roda de } \\
\text { conversar como com registro. }\end{array}$ & $\begin{array}{l}\text { - Planejar com os } \\
\text { estudantes como pode } \\
\text { realizar a investigação: } \\
\text { listando os animais de } \\
\text { estimação e anotando na } \\
\text { lousa, e levantando a mão } \\
\text { para indicar os animais } \\
\text { preferidos. } \\
\text { - Construir um instrumento. }\end{array}$ \\
\hline Dados & $\begin{array}{l}\text { - Aplicação dos } \\
\text { instrumentos. } \\
\text { - Aplicação dos } \\
\text { questionários. } \\
\text {-Entrevistas. }\end{array}$ & $\begin{array}{c}\text { - Matematizar com registro } \\
\text { para realizar a coleta dos } \\
\text { dados. }\end{array}$ & $\begin{array}{l}\text { - Realizar a indicação dos } \\
\text { animais preferidos } \\
\text { (levantando a mão) e anotar } \\
\text { na lousa. } \\
\text { - Responder o instrumento } \\
\text { construído. }\end{array}$ \\
\hline Análise & $\begin{array}{l}\text { - Análise e } \\
\text { interpretação dos } \\
\text { dados. }\end{array}$ & $\begin{array}{l}\text { - Matematizar com registro } \\
\text { para tratar os dados e analisar } \\
\text { e interpretar os dados obtidos. } \\
\text { - Matematizar na roda de } \\
\text { conversa para dialogar e } \\
\text { socializar a respeito dos } \\
\text { procedimentos de análise. }\end{array}$ & $\begin{array}{l}\text { - Partir dos dados brutos da } \\
\text { lousa ou do instrumento } \\
\text { construído dispostos no } \\
\text { banco de dados, e proceder } \\
\text { às transformações em } \\
\text { tabelas ou gráficos e depois } \\
\text { a distribuição percentual. }\end{array}$ \\
\hline Conclusão & $\begin{array}{l}\text { - Análise e reflexão } \\
\text { de todo o processo. }\end{array}$ & $\begin{array}{c}\text { - Matematizar com registro } \\
\text { para interpretar os resultados. } \\
\text { - Verificar a coerência entre } \\
\text { os dados e os objetivos } \\
\text { pretendidos. } \\
\text { - Matematizar na roda de } \\
\text { conversa momento para } \\
\text { refletir e agir de forma a } \\
\text { corrigir eventuais erros ou }\end{array}$ & $\begin{array}{l}\text { - Criar condições para que } \\
\text { os estudantes reflitam sobre } \\
\text { os resultados e extraiam } \\
\text { conclusões baseados nos } \\
\text { resultados e apresentem } \\
\text { implicações da pesquisa. }\end{array}$ \\
\hline
\end{tabular}




\begin{tabular}{|c|c|c|}
\hline & falhas. \\
& $\begin{array}{c}\text { Como proceder a divulgação } \\
\text { dos resultados. }\end{array}$ & \\
\hline
\end{tabular}

Fonte: Elaborado a partir dos estudos do Projeto em Rede D-Estat

O Quadro 1 exemplifica como o professor pode trabalhar com o Ciclo Investigativo e manter uma rotina didática em sala de aula, iniciando com o primeiro momento de estimular para que o estudante participe da pesquisa e contextualizar (Matematizar com jogos e desafios) para 0 desenvolvimento da ação investigativa, seguido do momento de socializar o conhecimento dos conceitos (Matematizar na roda de conversa) e, o terceiro momento de institucionalização dos conceitos matemáticos trabalhados (Matematizar com registro).

As definições apresentadas buscam fomentar a base para a construção de sequências de ensino tomando como fundamentação as fases do Ciclo Investigativo. E, assim, trabalhar com conceitos estatísticos e com a iniciação a investigação.

\section{Procedimentos metodológicos}

Este estudo caracteriza-se por uma abordagem qualitativa e exploratória (GIL, 2002), pois se preocupa em contribuir para evidenciar as discussões acerca de uma temática, neste caso, 0 Ciclo Investigativo e o ensino de conceitos estatísticos. Essencialmente, de um levantamento bibliográfico para a observação da problemática discutida na perspectiva de um grupo de pesquisa, configurando, assim, a natureza dessa exploração. Nesse sentido, propomos fazer um levantamento acerca das produções científicas, feitas por um grupo de pesquisa, relativas ao uso do Ciclo Investigativo para o ensino ou aprendizagem de conceitos estatístico. Analisamos as publicações científicas do grupo no intuito de serem os nossos materiais para levantamento dos dados, que, por sua vez, segundo Gil (2002), é uma das principais ferramentas para esse tipo de pesquisa, pois pesquisas científicas buscam apresentar uma discussão sobre um tema, assim como se constituem em resultados mais elaborados.

Para alcançar o objetivo de nosso estudo, recorremos ao site do Grupo de Pesquisa em Educação Matemática, Estatística e em Ciências que disponibiliza um acervo de suas publicações feitas em revistas, anais de eventos, em formato de trabalho de conclusão de curso, dissertações e teses desenvolvidas no âmbito das pesquisas do grupo, configurando suas produções científicas.

Reunimos no total sete trabalhos (ver Quadro 2), sendo três artigos em periódicos, duas 
dissertações de mestrado e, publicado em evento científico, um artigo e um relato de experiência. Publicações que tinham como objetivo apresentar resultados dos estudos com o ensino de conceitos estatísticos e o uso de sequências de ensino baseadas no Ciclo Investigativo. De posse desse material, em nossa análise, preocupamo-nos em explorar os objetivos principais dos trabalhos, sobretudo quanto aos procedimentos praticados e os resultados encontrados com 0 intuito de promover o ensino de conceitos estatísticos.

A seguir, apresentamos, no Quadro 2, as referências das produções que reunimos provenientes da nossa busca no site do grupo de pesquisa.

Quadro 2: Publicações científicas analisadas

\begin{tabular}{|c|c|}
\hline Notação & Referência da produção científica \\
\hline AP1 & $\begin{array}{l}\text { CAZORLA, Irene Mauricio; SILVA JUNIOR, Antônio Vidal da; SANTANA, Eurivalda } \\
\text { Ribeiro dos Santos. Reflexões sobre o ensino de variáveis conceituais na educação } \\
\text { básica. REnCiMa, São Paulo, v. 9, n. 2, p. } 354-373 \text {, abr.jun. } 2018 \text {. }\end{array}$ \\
\hline AP2 & $\begin{array}{l}\text { LÔBO, Wériton de Souza; CAZORLA, Irene Mauricio. Ensino de Estatística e o cuidado } \\
\text { com a saúde do adolescente. Educação Matemática em Revista - RS, Rio Grande, v. } 1 \text {, } \\
\text { n. } 20 \text {, p. } 120-129,2019 \text { b. }\end{array}$ \\
\hline AP3 & $\begin{array}{l}\text { ALVES, Heloisa Carvalho; SANTANA, Eurivalda Ribeiro dos Santos. Uma sequência de } \\
\text { ensino para o trabalho com conceitos estatísticos. Educação Matemática em Foco, } \\
\text { Campina Grande, v. 8, n. 2, p. 93-115, maio/ago. 2019. }\end{array}$ \\
\hline D1 & $\begin{array}{l}\text { SILVA JUNIOR, Antonio Vital da. Efeitos do Ciclo Investigativo PPDAC e das } \\
\text { transformações de representações semióticas no desenvolvimento de conceitos } \\
\text { estatísticos no Ensino Fundamental. 2018. 208f. Dissertação (Mestrado em Educação } \\
\text { Matemática) - Departamento de Ciências Exatas e Tecnológicas. Universidade Estadual } \\
\text { de Santa Cruz. Ilhéus. }\end{array}$ \\
\hline $\mathrm{D} 2$ & $\begin{array}{l}\text { LÔBO, Wériton de Souza. Limites e potencialidades de uma sequência de ensino para a } \\
\text { ampliação do conceito de média aritmética. 2019. Dissertação (Mestrado em Educação } \\
\text { Matemática) - Departamento de Ciências Exatas e Tecnológicas. Universidade Estadual } \\
\text { de Santa Cruz. Ilhéus. }\end{array}$ \\
\hline AE1 & $\begin{array}{l}\text { LÔBO, Wériton de Souza; CAZORLA, Irene Mauricio. A Estatística à serviço da saúde do } \\
\text { adolescente: o cartão de vacinação. In: ENCONTRO BAIANO DE EDUCAÇÃO } \\
\text { MATEMÁTICA, 18, 2019, Ilhéus. Anais do XVIII EBEM: A sala de aula de Matemática e } \\
\text { suas vertentes. Ilhéus: SBEM-BA, 2019b, p. 1-12. }\end{array}$ \\
\hline RE1 & $\begin{array}{l}\text { SILVA, Adriana Costa Santos da; SILVA FILHO, Deusdete Luiz da; NASCIMENTO, } \\
\text { Sandra Paula Almeida. Bullying, uma questão a ser analisada: estudando conceitos } \\
\text { estatísticos. In In: ENCONTRO BAIANO DE EDUCAÇÃO MATEMÁTICA, 18, 2019, } \\
\text { llhéus. Anais do XVIII EBEM: A sala de aula de Matemática e suas vertentes. Ilhéus: } \\
\text { SBEM-BA, 2019b, p. 1-8. }\end{array}$ \\
\hline
\end{tabular}

Fonte: Elaboração das Autoras

A fim de evitar possíveis repetições de títulos extensos (das publicações) ao longo da 
apresentação dos resultados, decidimos utilizar, para referirmo-nos a cada uma delas, a seguinte notação: AP para artigo em periódico; D para dissertação de mestrado; AE para artigo em evento; RE para relato de experiência em evento.

\section{Apresentação dos resultados}

O foco dos resultados está nas possibilidades metodológicas para o ensino de conceitos estatísticos, por meio do uso do Ciclo Investigativo. Por isso, destacamos uma síntese do objetivo, metodologia usada na implementação das sequências de ensino em sala de aula e os principais resultados referentes às aprendizagens observadas.

AP1: Reflexões sobre o ensino de variáveis conceituais na Educação Básica.

Esse artigo se refere a dados da dissertação de mestrado de um dos autores e tem como objetivo analisar a viabilidade e implicações didáticas de ensinar as variáveis conceituais, aquelas ligadas ao comportamento humano, com estudantes do $8^{\circ}$ ano do Ensino Fundamental. 0 referencial teórico foi o letramento estatístico na perspectiva de Gal (2002) e o Ciclo Investigativo de Wild e Pfannkuch (1999). A sequência de ensino pautada nas fases do PPDAC e o tema abordado foi "Hábitos Alimentares Saudáveis". Para a coleta de dados, os autores construíram uma Escala de Hábitos Alimentares Complementares - EHAC, do tipo Likert, com três itens positivos e três negativos. Para resguardar a fidedignidade das respostas dos estudantes os autores escolheram elaborar a escala $(P)$ e iniciar com os estudantes respondendo 0 instrumento de pesquisa (D). Depois os estudantes participaram de uma palestra ministrada por um nutricionista e, em seguida, elaboraram o problema de pesquisa $(P)$. Com o banco de dados, os estudantes calcularam medidas de tendência central e construíram tabelas e gráficos $(A)$. Na fase da conclusão $(C)$, os estudantes foram questionados e estimulados à reflexão sobre a questão de pesquisa.

Os autores afirmam que o desenvolvimento da sequência baseada no PPDAC com o tema hábitos alimentares e, com os estudantes tratando seus próprios dados e analisando os resultados, contribuiu significativamente para a tomada de consciência. Os estudantes perceberam que precisam dar mais valor ao consumo de alimentos naturais em detrimento dos industrializados. Os resultados indicam que foi possível: o tratamento estatístico dos dados em contexto; desvendar as implicações didáticas do ensino das variáveis conceituais; discutir os aspectos intrínsecos à mensuração de fenômenos não observáveis; a tomada de consciência dos estudantes sobre seus hábitos alimentares; trabalhar na perspectiva do letramento estatístico. 
* AP2: Ensino de estatística e o cuidado com a saúde do adolescente.

Este artigo reporta à uma elaboração colaborativa, de uma sequência de ensino de Estatística, por pesquisadores e uma professora, feita durante um processo formativo numa escola. A professora desenvolveu a sequência numa turma do $9^{\circ}$ ano do Ensino Fundamental. 0 artigo tem como objetivo apresentar as potencialidades da sequência, para o ensino de Estatística na Educação Básica, envolvendo o tema vacinação, na tomada de consciência dos adolescentes sobre o cuidado com sua saúde. A sequência foi construída sobre os princípios do letramento estatístico (GAL, 2002) e do Ciclo Investigativo. Os estudantes participaram, ativamente, de todas as fases do PPDAC.

O tema foi apresentado numa palestra com uma enfermeira do Posto de Saúde do bairro; os estudantes elaboraram o problema, discutiram o planejamento da investigação e coletaram os dados de seus próprios cartões de vacinação. Na análise, construíram tabela de distribuição de frequência de dupla entrada, frequência absoluta e relativa (cobertura vacinal), gráfico de barras empilhadas e fizeram o cálculo da média aritmética.

$\mathrm{Na}$ conclusão, o problema de investigação foi respondido, individualmente, e alguns afirmaram que com as atividades desenvolvidas foram alertados a respeito da importância de tomar as vacinas, os riscos para a saúde, a importância da investigação estatística e que aprenderam os conceitos estatísticos abordados. Os autores enfatizam que os resultados indicam que o desenvolvimento da sequência de ensino, com base no Ciclo Investigativo, possibilita: dar significado aos conceitos estatísticos; ampliar o conhecimento de contexto e do papel como tomadores de decisão; e, compreender a importância da Estatística na leitura de mundo.

* AP3: Uma sequência de ensino para o trabalho com conceitos estatísticos.

O artigo apresenta resultados de um planejamento realizado de maneira colaborativa, entre professores dos Anos Iniciais do Ensino Fundamental e pesquisadores da universidade, ao longo de um processo formativo que participaram. $\mathrm{O}$ objetivo do artigo é analisar os elementos de uma sequência de ensino, com o tema saúde bucal, que possibilitam o trabalho com componentes do letramento estatístico no $1^{\circ}$ e $2^{\circ}$ anos do Ensino Fundamental. 0 suporte metodológico foi 0 Ciclo Investigativo e, a fundamentação teórica o Letramento Estatístico (GAL, 2002) e a Teoria dos Campos Conceituais.

Para iniciar a sequência de ensino, o tema foi colocado numa palestra feita por profissionais da saúde e na apresentação de um vídeo disponível na internet sobre saúde bucal. O problema de investigação foi elaborado pelos estudantes com orientação das professoras - 
cada turma elaborou um problema. 0 instrumento de pesquisa foi construído pelas professoras, que preferiram abordar no instrumento questões sobre a alimentação dos estudantes; 0 instrumento foi impresso e entregue aos estudantes. Os dados foram coletados pelos estudantes em suas residências.

Para a análise, em cada turma, o banco de dados foi construído, coletivamente, com a orientação da professora. Os estudantes construíram em seu caderno: tabela simples e gráfico de colunas; e, fizeram a transformação da representação estatística secundária de tabela para gráfico. Os resultados da pesquisa indicam que os elementos da sequência de ensino possibilitaram o trabalho com o componente cognitivo do letramento estatístico, pois as fases do Ciclo Investigativo facilitaram o trabalho com conhecimentos estatísticos, com o conhecimento de contexto e o componente disposicional no que se refere a crenças e atitudes (GAL, 2002).

* D1: Efeitos do Ciclo Investigativo PPDAC e das transformações de representações semióticas no desenvolvimento de conceitos estatísticos no Ensino Fundamental.

Se refere aos resultados da dissertação de mestrado que, também, produziu os dados do artigo AP1. Teve como objetivo identificar e caracterizar os efeitos do Ciclo Investigativo e das transformações de representações semióticas no desenvolvimento de conceitos estatísticos no Ensino Fundamental, na perspectiva do letramento estatístico de Gal (2002). O pesquisador era professor de duas turmas do $8^{\circ}$ ano; o delineamento da pesquisa foi constituído de grupo experimental (GE) e grupo controle (GC).

O tema foi hábitos alimentares, na turma GC foram utilizados exemplos e atividades dos livros didáticos de Matemática adotados na escola, sem usar a sequência de ensino. Na turma GE foram utilizados os dados sobre os hábitos alimentares dos próprios estudantes, com a sequência de ensino baseada nas cinco fases do PPDAC. Dentre os principais resultados, os autores mostram o ganho substancial na aprendizagem de ambos os grupos - o GC triplicou seu desempenho médio o GE quadriplicou —, embora essa diferença não tenha sido significativa; contudo os estudantes do GE que iniciaram com baixo desempenho, conseguiram melhor desempenho do que os estudantes do GC. Os conceitos estatísticos foram: medidas de tendência central, tabelas e gráficos estatísticos.

Com a turma GE, os autores afirmam que o desafio foi tratar um volume grande de dados reais, e foi preciso trabalhar com os estudantes em duplas e, essa divisão, permitiu ao estudante ver como cada variável se comportava, e a comparação da frequência do consumo com a consciência acerca desse consumo de alimentos saudáveis e prejudiciais à saúde despertou neles 
uma postura crítica, fazendo com que se apropriassem do significado dos conceitos estatísticos em contexto, dando sinais da presença do letramento estatístico.

* D2: Limites e potencialidades de uma sequência de ensino para a ampliação do conceito de média aritmética.

Dissertação de mestrado que, também, produziu os dados do artigo AP2. Com objetivo de investigar os limites e potencialidades de uma sequência de ensino construída para ampliar 0 conceito de média aritmética, pautada nos princípios do Ciclo Investigativo e do Letramento Estatístico de Gal (2002).

No referencial, foi usada a Teoria dos Campos Conceituais com uma primeira aproximação do campo conceitual da média. A professora de Matemática, da turma do $9^{\circ}$ ano do Ensino Fundamental, implementou a sequência de ensino com o tema "Cartão de vacinação". A sequência seguiu as fases do Ciclo Investigativo com a participação ativa dos estudantes. Trabalharam com: banco de dados, tabelas, gráficos e calcularam média e ao final responderam à questão de investigação.

Os resultados indicam: envolvimento dos estudantes e ampliação do domínio de conceitos estatísticos, mas não foi possível trabalhar todas as propriedades e representações da média. Os autores concluem que é preciso combinar outras estratégias que possibilitem abranger o domínio do campo conceitual da média aritmética.

* AE1: A Estatística à serviço da saúde do adolescente: o cartão de vacinação.

Este trabalho apresenta um recorte dos estudos feitos para D2. Com o objetivo de apresentar o desenvolvimento de uma sequência de ensino pautada no Ciclo Investigativo, visando o desenvolvimento do letramento estatístico, com o tema imunização humana, via vacinação. A sequência de ensino foi desenvolvida numa turma de $9^{\circ}$ ano, conforme as fases do Ciclo Investigativo (ver detalhes em AP2 e D2).

Os resultados desse estudo mostram que dentro da realização das fases do Ciclo Investigativo, os estudantes se envolveram em todo o processo e despertaram a consciência da importância da vacinação para sua saúde, fazendo com que se apropriassem dos significados e propriedades dos conceitos estatísticos, dentre eles a média aritmética, sinalizando rudimentos do letramento estatístico. Estimulados com os resultados em sala de aula, os estudantes participaram da II Feira de Matemática da Universidade Estadual de Santa Cruz, momento que apresentaram os resultados obtidos em sala de aula e, replicaram parte da investigação com os visitantes da II Feira. 
* RE1: Bullying, uma questão a ser analisada: estudando conceitos estatísticos.

Esse é um relato de experiência feito por dois professores que participam do processo formativo e, também, são integrantes do Grupo de Pesquisa em Educação Matemática, Estatística e em Ciências, em parceria com uma das pesquisadoras que os acompanha na escola.

A publicação tem como objetivo apresentar 0 relato de um dos professores ao implementar, numa turma do $3^{\circ}$ ano do Ensino Fundamental, a sequência de ensino planejada e desenvolvida com as fases do Ciclo Investigativo. A fase do problema foi instalada com uma palestra proferida por uma assistente social, que apresentou um vídeo a respeito do bullying e discutiu o conceito com os estudantes.

O problema foi elaborado em diálogo entre o professor e os estudantes. Nesse momento, o professor foi questionando a turma sobre o que é investigar e, eles participaram ativamente e elaboraram o instrumento de coleta de dados. Os estudantes do $3^{\circ}$ ano fizeram a coleta de dados numa turma de $5^{\circ}$ ano - turma do segundo autor do RE1 - e, para a análise, o professor discutiu com os estudantes sobre: variável, tabelas simples e de dupla entrada, moda e gráfico de colunas.

Os estudantes fizeram as representações estatísticas em seus cadernos, sempre com a orientação do professor e o diálogo entre eles. Para a fase da conclusão, foi retomada a questão de investigação e os estudantes foram orientados a responder a partir das tabelas, do gráfico e da moda. Os autores mostram que, o desenvolvimento da sequência de ensino, ajudou na construção do conhecimento por meio da interação entre os estudantes e o professor, contribuindo, assim, para o desenvolvimento do pensamento e do letramento estatístico não apenas dos estudantes, mas de professores e pesquisadores.

\section{Considerações}

Pesquisadores da área de Educação tem apontado que no ensino tradicional o professor assume o papel de transmissor do conhecimento para o estudante, "no ensino tradicional, a sala de aula serve para o professor transmitir informação ao aluno, que após a aula, deve estudar 0 material abordado e realizar a atividade de avaliação para mostrar que esse material foi assimilado" (VALENTE, 2018, p. 29), sendo que com esse procedimento de prática pedagógica, 0 maior papel que o estudante assume é de receptor do conhecimento. Contudo, com o advento das novas tecnologias e, dos avanços das possibilidades de disseminação do conhecimento, é preciso repensar os papéis do professor e do estudante. 
Passa a ser fundamental que o professor tenha um papel de orientador, que auxilie 0 estudante a construir roteiros, caminhos e cenários para a construção de sua aprendizagem. Com essas orientações, os estudantes assumem um papel mais ativo no percurso de construção de sua própria aprendizagem (MORAN, 2018).

Em consonância com esses pressupostos, a BNCC, que é um documento oficial do sistema educacional brasileiro, orienta desenvolvimentos de competências que levem o estudante ao "aprender a aprender, saber lidar com a informação cada vez mais disponível, [...] aplicar o conhecimento para resolver problemas, ter autonomia para tomar decisões, ser proativo para identificar os dados de uma situação e buscar soluções, conviver e aprender com as diferenças e as diversidades" (BRASIL, 2017, p. 14). E, além disso, indica, dentre as dez competências gerais propostas para serem desenvolvidas com os estudantes da Educação Básica, a mobilização do pensamento científico e seus critérios. O que consubstancia a proposta de um fazer pedagógico que assuma o estudante como ativo, protagonista para a sua própria aprendizagem e, com competências para exercitar a sua curiosidade científica e investigadora.

Partindo de embasamento de resultados de pesquisas, reflexões teóricas e de orientações de documentos oficiais do sistema educacional, é preciso que a prática de ensino de Matemática seja experenciada com metodologias que propiciem o fazer e que ancore o estudante num papel ativo, protagonista e com um perfil investigador.

A proposta de Wild e Pfannkuch (1999) é que o ensino de conceitos estatísticos seja realizado por meio do Ciclo Investigativo. Essa abordagem metodológica, em sala de aula, tem favorecido o desenvolvimento do protagonismo do estudante para a aprendizagem de conceitos estatísticos, bem como do pensamento científico, como é possível constatar nos resultados obtidos dos estudos de Cazorla, Silva Junior e Santana (2018), Vital (2018), Alves e Santana (2019), Lôbo e Cazorla (2019a, 2019b), Lôbo (2019), Silva, Silva e Nascimento (2019).

As reflexões oriundas dos resultados das pesquisas realizadas pelo Grupo de Pesquisa em Educação Matemática, Estatística e em Ciências, a respeito das possibilidades metodológicas para o ensino de conceitos estatístico, por meio do uso de uma metodologia investigativa têm indicado que o Ciclo Investigativo proposto por Wild e Pfannkuch (1999) possibilita o ensino de conceitos estatísticos com sentido, a abordagem de temáticas de contextos de realidades escolar e da comunidade que o estudante convive, como: hábitos alimentares, vacinação, bullying e saúde bucal. Além disso, a aplicabilidade, em sala de aula, dos princípios do pensamento científico e 0 desenvolvimento de elementos do letramento estatístico - conceitos estatísticos, crenças e atitudes -, proporcionados pela própria constituição das fases do Ciclo Investigativo. 
Resultados que vão ao encontro das orientações da BNCC (BRASIL, 2017) para mobilização de competências que viabilizem o pensamento científico e seus critérios, com a elaboração de problemáticas, elaboração de instrumentos de pesquisa, a coleta de dados, 0 tratamento dos dados e a comunicação de resultados. Sendo essas fases que se aproximam do fazer científico rigoroso, mas se aproxima, também, do estudante enquanto aprendiz que pode ser orientado para a construção de seu próprio conhecimento, e se aproximando do fazer científico estabelecido pelas civilizações ao longo dos séculos.

Ressalta-se, também, nos resultados, as possibilidades metodológicas para o ensino de conceitos estatísticos nos Anos Iniciais e finais do Ensino Fundamental. Em todos os estudos, fica evidente 0 interesse despertado nos estudantes durante a realização de todas as fases do Ciclo, além de resultados que foram para além das fronteiras da escola, ao participarem da Feira de Matemática na Universidade.

Foram observadas limitações quanto a elaboração do instrumento de pesquisa, pois devido às nuances do rigor e a ética da pesquisa, os professores chegam a entregar o instrumento de coleta de dados pronto aos estudantes. Outra observação, é que podem ser gerados muitos dados e dificultar o tratamento, o que requer cuidados na elaboração do instrumento de pesquisa. A pesquisa de Lôbo e Cazorla (2019a, 2019b) ressaltam que outras metodologias de ensino precisam ser adotadas para o ensino de propriedades de conceitos estatísticos, no caso a média aritmética.

Diante dos resultados, evidenciamos as potencialidades do trabalho com 0 Ciclo Investigativo, mas observamos que existem limitações que precisam ser consideradas para 0 trabalho em sala de aula.

\section{Referências}

ALVES, Heloisa Carvalho; SANTANA, Eurivalda Ribeiro dos Santos. Uma sequência de ensino para o trabalho com conceitos estatísticos. Educação Matemática em Foco, Campina Grande, v. 8, n. 2, p. 93-115, maio/ago. 2019.

BRASIL. Ministério da Educação. Secretaria de Educação Básica. Base Nacional Comum Curricular. Brasília: MEC/SEB, 2017.

BRASIL. Ministério da Educação. Secretaria de Ensino Fundamental. Parâmetros Curriculares Nacionais: Terceiro e Quarto Ciclos do Ensino Fundamental - Matemática. Brasília: MEC/SEF, 1998.

BRASIL. Ministério da Educação. Secretaria de Ensino Fundamental. Parâmetros Curriculares Nacionais: Matemática. Brasília: MEC/SEF, 1997. 
CAZORLA, Irene Mauricio; SANTANA, Eurivalda Ribeiro dos Santos. Do Tratamento da Informação ao Letramento Estatístico. Itabuna: Via Litterarum, 2010.

CAZORLA, Irene Mauricio; SILVA JUNIOR, Antônio Vidal da; SANTANA, Eurivalda Ribeiro dos Santos. Reflexões sobre o ensino de variáveis conceituais na educação básica. REnCiMa, São Paulo, v. 9, n. 2, p. 354-373, abr./jun. 2018.

GAL, Iddo. Adults' Statistical Literacy: meanings, components, responsibilities. International Statistical Review, v. 70, n. 1, p. 1-25, apr. 2002.

GIL, Antônio Carlos. Como elaborar projetos de pesquisa. 4. ed. São Paulo: Atlas, 2002.

LÔBO, Wériton de Souza. Limites e potencialidades de uma sequência de ensino para a ampliação do conceito de média aritmética. 2019. Dissertação (Mestrado em Educação Matemática) Departamento de Ciências Exatas e Tecnológicas. Universidade Estadual de Santa Cruz. Ilhéus.

LÔBO, Wériton de Souza; CAZORLA, Irene Mauricio. A Estatística à serviço da saúde do adolescente: 0 cartão de vacinação. In: ENCONTRO BAIANO DE EDUCAÇÃO MATEMÁTICA, 18, 2019, Ilhéus. Anais do XVIII EBEM: A sala de aula de Matemática e suas vertentes. Ilhéus: SBEM-BA, 2019b, p. 1-12.

LÔBO, Wériton de Souza; CAZORLA, Irene Mauricio. Ensino de Estatística e o cuidado com a saúde do adolescente. Educação Matemática em Revista - RS, Rio Grande, v. 1, n. 20, p. 120$129,2019 \mathrm{~b}$.

MARCONI, Marina de Andrade; LAKATOS, Eva Maria. Fundamentos de Metodologia Científica. 7. ed. São Paulo, Atlas, 2010.

MORAN, José. Metodologias Ativas para uma aprendizagem mais profunda. In: $\mathrm{BAClCH}$, Lilian; MORAN, José. (Org). Metodologias ativas para uma educação inovadora: uma abordagem teóricoprática. Porto Alegre: Penso, 2018, p. 2-25.

PONTE, João Pedro da; BROCARDO, Joana; OLIVEIRA, Hélia. Investigações matemáticas na sala de aula. 3. ed. rev. ampl. Belo Horizonte: Autêntica, 2013.

SANTANA, Eurivalda Ribeiro dos Santos. Adição e subtração: o suporte didático influencia a aprendizagem do estudante? Ilhéus: Editus, 2012.

SANTANA, Eurivalda Ribeiro dos Santos; TAXA-AMARO, Fernanda de Oliveira Soares; LUNA, Ana Virgínia Almeida; BORTOLOTI, Roberta D’Angela Menduni; PEROVANO, Ana Paula. Alfabetização Matemática: proposta didática do professor. $2^{\circ}$ ano. Salvador: SEE-BA/IAT, 2015.

SILVA JUNIOR, Antonio Vital da. Efeitos do Ciclo Investigativo PPDAC e das transformações de representações semióticas no desenvolvimento de conceitos estatísticos no Ensino Fundamental. 2018. 208f. Dissertação (Mestrado em Educação Matemática) - Departamento de Ciências Exatas e Tecnológicas. Universidade Estadual de Santa Cruz. Ilhéus.

SILVA, Adriana Costa Santos da; SILVA FILHO, Deusdete Luiz da; NASCIMENTO, Sandra Paula Almeida. Bullying, uma questão a ser analisada: estudando conceitos estatísticos. In In: ENCONTRO BAIANO DE EDUCAÇÃO MATEMÁTICA, 18, 2019, Ilhéus. Anais do XVIII EBEM: A sala de aula de Matemática e suas vertentes. Ilhéus: SBEM-BA, 2019b, p. 1-8. 
TARDIF, Maurice. Saberes docentes e formação profissional. Tradução de Francisco Pereira. 17. ed. Petrópolis: Vozes, 2014.

VALENTE, José Armando. A sala de aula invertida e a possibilidade do ensino personalizado: uma experiência com a graduação em midialogia. In: BAClCH, Lilian; MORAN, José. (Org). Metodologias ativas para uma educação inovadora: uma abordagem teórico-prática. Porto Alegre: Penso, 2018, p. 26-44.

WILD, Chris J.; PFANNKUCH, Maxine. Statistical thinking in empirical enquiry. International Statistical Review, v. 67, n. 3, p. 223-248, dec. 1999. 